\title{
Spirometry Assessment and Correlation With Postoperative Pulmonary Complications in Cardiac Surgery Patients
}

\author{
Masood Alam ${ }^{1}$, Muhammad Imran Shehzad ${ }^{1}$, Shafqat Hussain ${ }^{2}$, Iftikhar Paras ${ }^{2}$, Masooma Kanwal ${ }^{3}$, \\ Azam Mushtaq ${ }^{4}$ \\ 1. Pulmonology, Chaudhary Pervaiz Elahi Institute of Cardiology, Multan, PAK 2. Cardiac Surgery, Chaudhary Pervaiz \\ Elahi Institute of Cardiology, Multan, PAK 3. Physical Therapy, Choudhary Pervez Elahi Institute of Cardiology, Multan, \\ PAK 4. Pulmonology, Quaid-e-Azam Medical College, Bahawalpur, PAK
}

Corresponding author: Masood Alam,dr.masood174@gmail.com

\section{Abstract \\ Objective}

To observe spirometry and its correlation with postoperative pulmonary complications in cardiac surgery patients.

\section{Study design}

Prospective observational study

\section{Place and duration of the study}

Chaudhary Pervaiz Elahi Institute of Cardiology (CPEIC) Multan, from January 1, 2017, to June 30, 2020

\section{Methodology}

Written informed consent was taken from 357 patients. Spirometry was performed in all the patients using the conventional method. Baseline data, including gender, age, body mass index (BMI), living area, smoking history, known lung illness, six-minute walk distance, predicted forced vital capacity (FVC) \%, predicted forced expiratory volume in one second (FEV1) \%, and type of the procedure such as aortic valve replacement (AVR), coronary artery bypass grafting (CABG), double-valve replacement (DVR), and mitral valve replacement (MVR) were documented for all the patients. Outcome data included postoperative ICU length of stay (LOS), respiratory failure, respiratory infection, atelectasis, and mortality.

\section{Results}

Received 09/06/2020

Review began 10/01/2020 Review ended 10/17/2020 Published 10/23/2020

\section{(๑) Copyright 2020}

Alam et al. This is an open access article distributed under the terms of the Creative Commons Attribution License CC-BY 4.0., which permits unrestricted use, distribution, and reproduction in any medium, provided the original author and source are credited.
The most common procedure was CABG and MVR proceeded by $n=254$ (71.1\%) and $n=83$ (23.2\%) patients, respectively. Postoperative complications, such as respiratory failure, respiratory infection, and atelectasis, was noted in $n=29$ (8.1\%), $n=28$ (7.8\%), and $n=127$ (35.6\%) patients, respectively, while $n=5$ (1.4\%) patients died.

\section{Conclusion}

Deranged pulmonary function tests (PFTs) are associated with poor prognosis following elective cardiac surgery in terms of postoperative pulmonary complications such as pulmonary infection, respiratory failure, and atelectasis. There is a significant difference in percentage predicted of FVC and FEV1 in patients who developed atelectasis and respiratory tract infection.

Categories: Anesthesiology, Cardiology, Pulmonology

Keywords: cardiac surgery, postoperative pulmonary complications, spirometry

\section{Introduction}

Almost 32,000 elective cardiac surgeries have been performed in Australia, from 2013 to 2017, and postoperative ICU support was required in most of the cases [1]. Significant occupancy pressure on intensive care units (ICUs) is caused by cardiac surgeries. Many elective procedures are canceled due to the lack of availability of beds in the ICU facilities and this, in turn, leads to the waste of the anesthetic, theatre, and surgical resources. Estimation of the ICU length of stay (LOS) is required for the successful planning of the surgical and theater facilities, for which available data needs to be analyzed. Postoperative respiratory failure and preexisting lung diseases require prolonged mechanical ventilation and lead to prolongation on ICU LOS [2-4]. 
There is a significant co-existence of cardiac and pulmonary disease and most of the patients who are candidates for cardiac surgery have preexisting pulmonary pathology. The important correlation of lung function and cardiac surgical outcomes is emphasized by the prognostic value of chronic lung disease assessment in the Society of Thoracic Surgeons (STS) and EuroSCORE II operative mortality estimation tools [5-10]. The poor outcome of cardiac surgery has been observed in those with a decreased diffusing capacity of the lungs for carbon monoxide (DLCO) [10]. The relationship of presence and severity of COPD with arrhythmias has been observed in population studies [11].

There has been some inconsistent data regarding the relation of risk of arrhythmias following cardiac surgery with COPD. Many healthcare facilities perform pulmonary function tests routinely for the identification and quantification of lung disease which can, later on, lead to anesthesia complications and poor postoperative prognosis. It has been identified from the evaluation of many pulmonary function tests (PFTs) that the duration of mechanical ventilation and LOS in ICU after cardiac surgery can be predicted from the obstructive respiratory patterns [12]. However, resources are needed for performing spirometry, and it also involves the discomfort of arterial blood sampling, which is not convenient for the patients.

As local data is not sufficient regarding the prediction of the ICU LOS and postoperative pulmonary complications after cardiac surgery from the spirometric evaluation, we conducted this study to test the hypothesis that PFTs can help in the identification of the patients who are more likely to require mechanical ventilation postoperatively.

\section{Materials And Methods}

This prospective, observational study was conducted on 357 patients who underwent elective cardiac surgery in Chaudhary Pervaiz Elahi Institute of Cardiology (CPEIC) Multan, from January 1, 2017, to June 30, 2020. The study was started after ethical approval from the ethical board of CPEIC Multan under approval number 32/pulmo/CPEIC-2018. Patients of all age groups undergoing coronary artery bypass graft (CABG) surgery or valvular surgery were included in the study. Patients who had undergone any pulmonary surgery in the past, were a diagnosed case of malignant lung cancer, and with a smoking history of more than 45 pack-years were excluded from the study. Ethical approval was given by the hospital ethical review board.

Written informed consent was taken from all the patients, and the purpose of the study was explained. Spirometry was performed in all the patients using the conventional method. There was no difference in the anesthesia technique or the use of sedatives between the groups. Predicted forced vital capacity (FVC) and forced expiratory volume in one second (FEV1) were taken into consideration. Baseline data, including gender, age, body mass index (BMI), living area, smoking history, known lung illness, six-minute walk distance, predicted FVC \%, predicted FEV1 \%, and type of the procedure such as aortic valve regurgitation (AVR), CABG, double valve regurgitation (DVR), and mitral valve regurgitation (MVR) were documented for all the patients. COPD was diagnosed on the basis of post-bronchodilator FEV1<80\% of the predicted along with FEV1/FVC $<70 \%$ [13-14] as per criteria defined by the Global Initiative for Chronic Obstructive Lung Disease (GOLD), or those who had FEV1/FVC < lower limit of normal as per the criteria of Global Lung Initiative (GLI) [15]. Outcome data included postoperative ICU LOS, respiratory failure, respiratory infection, atelectasis, and mortality.

Data were entered and analyzed in the Statistical Package for the Social Sciences (SPSS) version 23.0. Predicted FVC \% and predicted FEV1 \% were compared between the two groups based on the postoperative incidence of respiratory failure, respiratory infection, atelectasis, and mortality. Continuous data, such as age, BMI, six-minute walk distance, predicted FVC \%, predicted FEV1 \%, and ICU LOS, were calculated as mean and standard deviation. Nominal data, such as gender, living area, smoking history, known lung illness, type of procedure, the postoperative incidence of respiratory failure, respiratory infection, atelectasis, and mortality, were documented as numbers and percentages. An independent t-test was applied and at $\mathrm{p} \leqslant 0.05$, the difference was considered statistically significant.

\section{Results}

Three-hundred and fifty-seven patients were included in this study, both genders. There were $\mathrm{n}=240$ (67.2\%) males and $\mathrm{n}=117$ (32.8\%) females, with mean age, and BMI of the patients was $49.02 \pm 15.13$ years $27.01 \pm 4.45$ $\mathrm{kg} / \mathrm{m} 2$, respectively. The mean ICU stay of the patients was $4.64 \pm 1.31$ days. The majority of the patients lived in rural areas, i.e. $\mathrm{n}=186$ (52.1\%), while $\mathrm{n}=171$ (47.9\%) patients lived in urban areas, $\mathrm{n}=154(43.1 \%)$ were smokers. Known respiratory illness was noted in $n=68$ (19\%) patients. The mean distance of six minutes' walk (preoperative) of the patients was $429.28 \pm 90.77$ meters. The mean \% predicted FVC and \% predicted FEV1 of the patients was $68.05 \pm 17.91$ and $70.54 \pm 18.31$, respectively. Different procedures were done for the treatment of the patients. The most common procedure was CABG and MVR proceeded by $\mathrm{n}=254(71.1 \%)$ and $n=83$ (23.2\%) patients, respectively. Postoperative complications, such as respiratory failure, respiratory infection, and atelectasis, was noted in $\mathrm{n}=29$ (8.1\%), $\mathrm{n}=28$ (7.8\%), and $\mathrm{n}=127$ (35.6\%) patients, respectively, while $\mathrm{n}=5(1.4 \%)$ patients died (Table 1$)$. 


\section{Cureus}

\begin{tabular}{|c|c|}
\hline Gender & \\
\hline Male & $\mathrm{n}=240(67.2 \%)$ \\
\hline Female & $n=117(32.8 \%)$ \\
\hline Age (years) & $49.02 \pm 15.13$ \\
\hline BMI $\left(\mathrm{kg} / \mathrm{m}^{2}\right)$ & $27.01 \pm 4.45$ \\
\hline ICU stay (days) & $4.64 \pm 1.31$ \\
\hline Living area & \\
\hline Rural & $\mathrm{n}=186(52.1 \%)$ \\
\hline Urban & $\mathrm{n}=171(47.9 \%)$ \\
\hline Smoking status & \\
\hline Yes & $n=154(43.1 \%)$ \\
\hline No & $n=203(56.9 \%)$ \\
\hline Known respiratory illness & \\
\hline Yes & $\mathrm{n}=68(19 \%)$ \\
\hline No & $\mathrm{n}=289(81 \%)$ \\
\hline Six minutes distance (meters) & $429.28 \pm 90.77$ \\
\hline$\%$ predicted FVC & $68.05 \pm 17.91$ \\
\hline$\%$ predicted $\mathrm{FEV}_{1}$ & $70.54 \pm 18.31$ \\
\hline Procedures done & \\
\hline AVR & $n=14(3.9 \%)$ \\
\hline CABG & $\mathrm{n}=254(71.1 \%)$ \\
\hline DVR & $\mathrm{n}=6(1.7 \%)$ \\
\hline MVR & $n=83(23.2 \%)$ \\
\hline Postoperative respiratory failur & \\
\hline Yes & $n=29(8.1 \%)$ \\
\hline No & $\mathrm{n}=328(91.9 \%)$ \\
\hline Respiratory infection & \\
\hline Yes & $\mathrm{n}=28(7.8 \%)$ \\
\hline No & $n=329(92.2 \%)$ \\
\hline Atelectasis & \\
\hline Yes & $n=127(35.6 \%)$ \\
\hline No & $\mathrm{n}=230(64.4 \%)$ \\
\hline Mortality & \\
\hline Yes & $\mathrm{n}=5(1.4 \%)$ \\
\hline No & $n=352(98.6 \%)$ \\
\hline
\end{tabular}

\section{TABLE 1: Demographic and baseline characteristics of the patients}

BMI: body mass index; ICU: intensive care unit; FVC: forced vital capacity; FEV1: forced expiratory volume in one second; AVR: aortic valve replacement; CABG: coronary artery bypass grafting; DVR: double-valve replacement; MVR: mitral valve replacement 


\section{Cureus}

The mean \% predicted FVC of respiratory failure and respiratory not-failure patients was $74.49 \pm 12.18$ and $67.48 \pm 18.22$, respectively. The mean \% predicted FVC of respiratory failure patients was greater than the mean respiratory not-failure patients. The difference was statistically significant, $(\mathrm{p}=0.043)$. While the mean $\%$ predicted FEV1 of respiratory failure and respiratory not-failure patients was $80.05 \pm 13.07$ and $69.70 \pm 18.47$, respectively. The mean \% predicted FEV1 of respiratory failure was greater than the mean respiratory not-failure patients. The difference was statistically significant, $(\mathrm{p}=0.003)$ (Table 2$)$.

\begin{tabular}{|c|c|c|c|}
\hline \multirow{3}{*}{ Variable } & \multicolumn{2}{|l|}{ Complication } & \multirow{3}{*}{ P-value } \\
\hline & \multicolumn{2}{|l|}{ Respiratory failure } & \\
\hline & Yes n=29 (8.1\%) & No $n=328(91.9 \%)$ & \\
\hline$\%$ predicted FVC & $74.49 \pm 12.18$ & $67.48 \pm 18.22$ & 0.043 \\
\hline$\%$ predicted $\mathrm{FEV}_{1}$ & $80.05 \pm 13.07$ & $69.70 \pm 18.47$ & 0.003 \\
\hline \multicolumn{4}{|l|}{ Respiratory infection } \\
\hline & Yes $\mathrm{n}=28(7.8 \%)$ & No $n=329(92.2 \%)$ & \\
\hline$\%$ predicted FVC & $74.63 \pm 7.56$ & $67.49 \pm 18.41$ & 0.043 \\
\hline$\%$ predicted $\mathrm{FEV}_{1}$ & $79.39 \pm 12.73$ & $69.78 \pm 18.52$ & 0.008 \\
\hline \multicolumn{4}{|l|}{ Atelectasis } \\
\hline & Yes n=127 (35.6\%) & No $n=230(64.4 \%)$ & \\
\hline$\%$ predicted FVC & $71.68 \pm 12.84$ & $66.05 \pm 19.91$ & 0.004 \\
\hline$\%$ predicted FEV 1 & $77.83 \pm 12.51$ & $66.51 \pm 19.72$ & 0.000 \\
\hline \multicolumn{4}{|l|}{ Mortality } \\
\hline & Yes n=5 (1.4\%) & No $n=352(98.6 \%)$ & \\
\hline$\%$ predicted FVC & $74.01 \pm 25.52$ & $67.97 \pm 17.80$ & 0.455 \\
\hline$\%$ predicted $\mathrm{FEV}_{1}$ & $75.60 \pm 25.50$ & $70.47 \pm 18.22$ & 0.534 \\
\hline
\end{tabular}

\section{TABLE 2: Comparison of postoperative complications with \% predicted FVC and \% predicted} FEV1

FVC: forced vital capacity; FEV1: forced expiratory volume in one second

The mean \% predicted FVC of respiratory infected and respiratory not-infected patients was $74.63 \pm 7.56$ and $67.49 \pm 18.41$, respectively. The mean \% predicted FVC of respiratory infected patients was greater than the mean respiratory not-failure patients. The difference was statistically significant $(\mathrm{p}=0.043)$ while the mean $\%$ predicted FEV1 of respiratory infected and respiratory not-infected patients was $79.39 \pm 12.73$ and $69.78 \pm 18.52$, respectively. The mean \% predicted FEV1 of respiratory infected patients was greater than the mean respiratory not-infected patients. The difference was statistically significant $(\mathrm{p}=0.008)$ (Table 2$)$.

The mean \% predicted FVC of atelectasis and non-atelectasis patients was $71.68 \pm 12.84$ and $66.05 \pm 19.91$, respectively. The mean \% predicted FVC of atelectasis patients was greater than the mean non-atelectasis patients. The difference was statistically significant $(\mathrm{p}=0.004)$ while the mean \% predicted FEV1 of atelectasis and non-atelectasis patients was $77.83 \pm 12.51$ and $66.51 \pm 19.72$, respectively. The mean \% predicted FEV1 of atelectasis patients was greater than the mean non-atelectasis patients. The difference was statistically significant, $(\mathrm{p}=0.000)$ (Table 2$)$.

The mean \% predicted FVC of patients who lived and who died was $74.01 \pm 25.52$ and $67.97 \pm 17.80$, respectively. The mean \% predicted FVC of died patients was greater than the mean of lived patients. The difference was statistically insignificant $(\mathrm{p}=0.455)$. While the mean \% predicted FEV1 of died and lived patients was $75.60 \pm 25.50$ and $70.47 \pm 18.22$, respectively. The mean \% predicted FEV1 of patients who died was greater than the mean who lived patients. The difference was statistically insignificant $(\mathrm{p}=0.534)$ (Table 2). 


\section{Discussion}

In our study, we observed that predicted FVC \% and predicted FEV1\% were most strongly associated with poor postoperative outcomes such as postoperative respiratory failure, atelectasis, and pulmonary infection. However, no significant association of predicted FVC \% and predicted FEV1\% was observed with postoperative mortality.

Elective cardiac surgery is a common surgical intervention, which has a substantial effect on surgical as well as intensive care resources. As the majority of the patients are of old age and have at least one underlying one chronic illness, perioperative intensive care is needed for cardiac surgery [16]. If not properly planned and predicted, the efficiency of services provided in cardiac surgery is severely affected by the postoperative demand for longer mechanical ventilation. Preoperative PFTs parameters have the ability to fully predict the postoperative requirement of ICU and pulmonary complications and, in turn, help in the perioperative planning. Skilled technical staff and sophisticated instruments are required to perform the PFTs, which is challenging. Moreover, the inappropriate use of the PFTs instrument is not convenient for the patients, and it puts a cost burden on the health care system.

Risk stratification scores, such as STS score and EuroSCORE 2, are influenced by the presence of chronic pulmonary diseases, and they need to be identified early [17]. A study found out that the OR for prolonged ventilation was 7.5 for the patients who had DLCO $<60 \%$ of the predicted and FVC $<80 \%$ of the predicted value but only $57 \%$ of the patients required prolonged ventilation and $14 \%$ needed ventilation for more than 48 hours [18].

Patients who have PFTs consistent with the diagnosis of COPD are more likely to experience postoperative arrhythmias [18]. The mechanisms involved with the high risk of postoperative arrhythmias in COPD patients are beta-agonist treatment and atrial remodeling [19]. There is an increased risk of stroke associated with atrial fibrillation experienced after cardiac surgery. Moreover, anticoagulation therapy is required in atrial fibrillation, and it is also associated with poor long-term survival of the patient [20-21].

The current study showed that there is a significant difference in terms of predicted FVC \% and predicted FEV1 \% between the patients who suffered from postoperative pulmonary complications such as respiratory failure, atelectasis, and pulmonary infections. However, there was no significant difference observed between the alive and dead groups.

\section{Conclusions}

Deranged PFTs are associated with poor prognosis following elective cardiac surgery in terms of postoperative pulmonary complications such as pulmonary infection, respiratory failure, and atelectasis. Therefore, there is a need to properly utilize the expertise of the healthcare personnel and other facilities to improve the postoperative prognosis in the patients who had deranged pulmonary function tests identified prior to surgery.

\section{Additional Information \\ Disclosures}

Human subjects: Consent was obtained by all participants in this study. Animal subjects: All authors have confirmed that this study did not involve animal subjects or tissue. Conflicts of interest: In compliance with the ICMJE uniform disclosure form, all authors declare the following: Payment/services info: All authors have declared that no financial support was received from any organization for the submitted work. Financial relationships: All authors have declared that they have no financial relationships at present or within the previous three years with any organizations that might have an interest in the submitted work. Other relationships: All authors have declared that there are no other relationships or activities that could appear to have influenced the submitted work.

\section{References}

1. Reddi BA, Johnston SD, Bart S, Chan JC, Finnis M: Abnormal pulmonary function tests are associated with prolonged ventilation and risk of complications following elective cardiac surgery. Anaesth Intens Care. 2019, 47:510-515. 10.1177/0310057X19877188

2. Saleh HZ, Mohan K, Shaw M, et al.: Impact of chronic obstructive pulmonary disease severity on surgical outcomes in patients undergoing non-emergent coronary artery bypass grafting. Eur J Cardiothorac Surg. 2012, 42:108-113. 10.1093/ejcts/ezr271

3. Najafi M, Sheikhvatan M, Mortazavi SH: Do preoperative pulmonary function indices predict morbidity after coronary artery bypass surgery?. Ann Card Anaesth. 2015, 18:293-298. 10.4103/0971-9784.159796

4. Manganas H, Lacasse Y, Bourgeois S, Perron J, Dagenais F, Maltais F: Postoperative outcome after coronary artery bypass grafting in chronic obstructive pulmonary disease. A meta-analysis. Can Respir J. 2007, 14:1924. 10.1097/MD.0000000000014388

5. Nashef SA, Roques F, Sharples LD, et al.: Euroscore II. Eur J Cardiothorac Surg. 2012, 41:734-745. 10.1093/ejcts/ezs043

6. Shahian DM, O'Brien SM, Filardo G, et al.: The Society of Thoracic Surgeons 2008 cardiac surgery risk 
models: part 3-valve plus coronary artery bypass grafting surgery. Ann Thorac Surg. 2009, 88:43-62. 10.1016/j.athoracsur.2009.05.055

7. O'Brien SM, Shahian DM, Filardo G, et al.: The Society of Thoracic Surgeons 2008 cardiac surgery risk models: part 2-isolated valve surgery. Ann Thorac Surg. 2009, 88:23-42. 10.1016/j.athoracsur.2009.05.056

8. Shahian DM, O'Brien SM, Filardo G, et al.: The Society of Thoracic Surgeons 2008 cardiac surgery risk models: part 1-coronary artery bypass grafting surgery. Ann Thorac Surg. 2009, 88:2-22. 10.1016/j.athoracsur.2009.05.053

9. Shahian DM, Edwards FH: The Society of Thoracic Surgeons 2008 cardiac surgery risk models: introduction . Ann Thorac Surg. 2009, 88:1. 10.1016/j.athoracsur.2009.05.054

10. McKeon J, McKeon N, Stevens S, Stewart H: Respiratory function tests prior to cardiac surgery: Prediction of post-operative outcomes. Eur Respir J. 2014, 44:1268.

11. Konecny T, Park JY, Somers KR, et al.: Relation of chronic obstructive pulmonary disease to atrial and ventricular arrhythmias. Am J Cardiol. 2014, 114:272-277.

12. McAllister DA, Wild SH, MacLay JD, et al.: Forced expiratory volume in one second predicts length of stay and in-hospital mortality in patients undergoing cardiac surgery: a retrospective cohort study. PLoS One. 2013, 8:64565. 10.1371/journal.pone.0064565

13. Ried M, Unger P, Puehler T, Haneya A, Schmid C, Diez C: Mild-to-moderate COPD as a risk factor for increased 30-day mortality in cardiac surgery. Thorac Cardiovasc Surg. 2010, 58:387-391. 10.1055/s-00301249830

14. Vogelmeier CF, Criner GJ, Martinez FJ, et al.: Global strategy for the diagnosis, management, and prevention of chronic obstructive lung disease 2017 report: GOLD executive summary. Eur Respir J. 2017, 49:1700214. 10.1164/rccm.201701-0218PP

15. Brazzale D, Hall G, Swanney MP: Reference values for spirometry and their use in test interpretation: a position statement from the Australian and New Zealand Society of Respiratory Science. Respirology. 2016, 21:1201-1209. 10.1111/resp.12855

16. Rashid M, Kwok CS, Gale CP, et al.: Impact of co-morbid burden on mortality in patients with coronary heart disease, heart failure, and cerebrovascular accident: a systematic review and meta-analysis. Eur Heart J Qual Care Clin Outcomes. 2017, 3:20-36. 10.1093/ehjqcco/qcw025

17. Ivanov A, Yossef J, Tailon J, et al.: Do pulmonary function tests improve risk stratification before cardiothoracic surgery?. J Thorac Cardiovasc Surg. 2016, 151:1183-1189.

18. Reddi BA, Johnston SD, Bart S, Chan JC, Finnis M: Abnormal pulmonary function tests are associated with prolonged ventilation and risk of complications following elective cardiac surgery. Anaesth Intens Care. 2019, 47:510-515. 10.1177/0310057X19877188

19. Ogi H, Nakano Y, Niida S, et al.: Is structural remodeling of fibrillated atria the consequence of tissue hypoxia?. Circ J. 2010, 74:1815-1821. 10.1253/circj.cj-09-0969

20. El-Chami MF, Kilgo P, Thourani V, et al.: New-onset atrial fibrillation predicts long-term mortality after coronary artery bypass graft. J Am Coll Cardiol. 2010, 55:1370-1376.

21. Shen J, Lall S, Zheng V, Buckley P, Damiano RJ Jr, Schuessler RB: The persistent problem of new-onset postoperative atrial fibrillation: a single- institution experience over two decades. J Thorac Cardiovasc Surg. 2011, 141:559-570. 10.1016/j.jtcvs.2010.03.011 